\title{
Safety evaluation of mine roof accident based on grey fuzzy comprehensive evaluation
}

\author{
Chunjing Gao ${ }^{1,2}$, Dongmei Huang ${ }^{1,2, *}$, Han $\mathrm{Xi}^{1,2}$, and Yingying $\mathrm{Zhu}^{2 *}$ \\ ${ }^{1}$ State Key Laboratory of Mining Disaster Prevention and Control Co-Founded by Shandong Province \\ and the Ministry of Science and Technology. \\ ${ }^{2}$ School of Safety and Environmental Engineering, Shandong University of Science and Technology, \\ Qingdao 266590, China.
}

\begin{abstract}
By analyzing the risk assessment methods of roof accidents at home and abroad, this paper summarizes the research status of risk assessment in this area, and analyzes the significance of risk assessment of mine roof accidents. The risk identification of roadway collapse accident is carried out from four aspects -- human, material, environment, and management, and the risk evaluation index system is established, including human unsafe behavior, material unsafe state, management factors and environmental factors. On this basis, the weight of index set is determined by grey relation analysis, and the fuzzy comprehensive evaluation model is obtained by combining the fuzzy comprehensive evaluation method. Taking a coal mine as an example, this paper makes an empirical study of risk assessment and puts forward corresponding countermeasures according to the results of comprehensive assessment. The results show that the safety level of the mine is very safe, so it is feasible to use the grey fuzzy comprehensive evaluation method to evaluate the safety of the mine, which can provide reference for the same kind of mine.
\end{abstract}

Coal is one of the important energy and mineral resources, accounting for $25 \%$ of the world's primary energy consumption. Coal is the most abundant and widely distributed energy in the world. At present, with the deepening of the mining depth and the increase of the tunnel section, the probability of mine disaster accidents is increasing, which seriously affects the safety production of coal enterprises.Statistics show that ${ }^{[1]}$, In 2018 , China's roof accidents accounted for $35 \%$ of coal mine safety accidents, and the number of deaths due to roof accidents accounted for $34 \%$ of the total. Therefore, in order to prevent and control roof accidents and ensure the safety and order of mining work, it is very important to evaluate the risk level of coal mine roof accidents.

In view of the risk grade evaluation and prevention methods of coal mine roof accidents, experts and scholars at home and abroad have carried out many aspects of research. Duzgun ${ }^{[2]}$ proposed a risk decision analysis method for risk assessment and management of underground roof collapse, which is a powerful technology to deal with uncertainty and

\footnotetext{
*Corresponding author: Dongmei Huang@sdust.edu.cn
} 
manage the risk of roof collapse; Palei ${ }^{[3]}$ analyzed the influence of each contribution parameter on the safety coefficient of support and the possibility of roof collapse by using the column working method. The results showed that the roof bolt density and the bolt anchoring strength had a positive influence on the safety coefficient of support, and the bolt spacing had a significant negative correlation with the safety coefficient of support; Maiti ${ }^{[4]}$ established the relative risk model of roof and side fall accidents by using the log linear analysis method of two-way contingency table, which was verified to be applicable to any industrial environment; Mahdevri ${ }^{[5]}$ proposed a human health risk assessment method based on Fuzzy TOPSIS, which can be used to identify potential risks and help to take appropriate measures; Behraftar ${ }^{[6]}$ adopts an improved risk priority number (MRPN) technology, and analyzes that roof collapse is the most important risk factor in coal mine accidents; Paul ${ }^{[7]}$ established an improved rock mass classification system (RMRdyn) for roof collapse accident to obtain the real foundation conditions of in-situ rock; Zhang ${ }^{[8]}$ established the fuzzy comprehensive evaluation model of coal mine roof accidents, and verified that the safety level of four coal mines is general; Jiang ${ }^{[9]}$ used the method of combining triangle fuzzy theory and traditional fault tree to make quantitative analysis on the risk sources of roof falling accident. The research shows that large area of empty support is the biggest risk source of roof falling accident; Wang ${ }^{[10]}$ Overcome the shortcomings of FTA through the shell theoretical model, and verify its feasibility through strength; Xie ${ }^{[11]}$ used the grey algebra curve model (GAM) to predict the roof separation. The practical application proves that GAM is very important for the early warning of roof falling accidents; Guan ${ }^{[12]}$ obtained the contour map of each characteristic point distribution by FLAC-3D software, which enables the area to be classified according to various safety factors; Zhang ${ }^{[13]}$ found that due to the influence of abandoned roadway and caving area in front of the working face, the roof of the working face had the characteristics of advanced fracture, so he proposed the pre filling scheme of abandoned roadway; $\mathrm{Xu}^{[14]}$ analyzed the causes of coal mine roof accidents, and put forward some measures to prevent coal mine roof accidents; Guo ${ }^{[15]}$ uses the risk analysis model of coal mine roof accident which combines the improved AHP and catastrophe theory to determine the safety level of a coal mine as general.

In solving the problem of frequent roof accidents in coal mines, most of the papers are not very comprehensive, and the research method is relatively simple. In order to solve the comprehensive problems of the interaction of economy, society, environment and technology, ensure the smooth progress of mining engineering, increase the safety of engineering and reduce the occurrence of accidents, this paper takes a coal mine as an example, considers the four important aspects of accidents, combines the grey fuzzy theory, and constructs the evaluation index system of roof accidents The grey relation analysis obtains the index weight, evaluates it, obtains the mine safety grade, and puts forward the corresponding preventive measures and the mine related management suggestions.

\section{Index system for risk assessment of mine roof accidents}

\subsection{Risk identification process of coal mine roof accident}

From the perspective of safety assessment management, the causes of coal mine roof accidents can be analyzed from four aspects: human, material, environment and management. Based on the principle of index system construction and combined with the characteristics of the mine, the main accident risk factors of the mine are summarized as follows:

(1) Human factors. As the name implies, it refers to the behavior that people have caused or may cause accidents in production activities. People are the most direct root cause of accidents. In the roof accident, it mainly includes the safety awareness of the staff, the 
empty roof operation and the professionalism of the operators.

(2) Equipment factors. It refers to the state of accidents caused by the possible release of energy of objects, and is the direct cause of accidents. Support problems, blasting equipment or safety thickness of roof are all likely to promote the occurrence of accidents.

(3) Environmental factors. The underground environment of coal mine is complex and the cost of maintenance and management is huge, so the possibility of accidents is very large. For example, coal seam pressure, unreasonable mining method and long exposure time of working face may have a great impact on underground rock mass. In addition, geological conditions, gas concentration and other issues must also be fully considered.

(4) Management factors. The underground engineering needs to bear a greater risk, which requires not only the quality and quantity of construction, but also the relevant departments of management problems during the mining operation to do their best, establish a comprehensive and effective management department and mechanism, and strengthen the daily inspection.

\subsection{Establishment of evaluation index of coal mine roof accident}

According to the above risk identification, the risk assessment index system of coal mine roof accident is established, as shown in Figure 1.

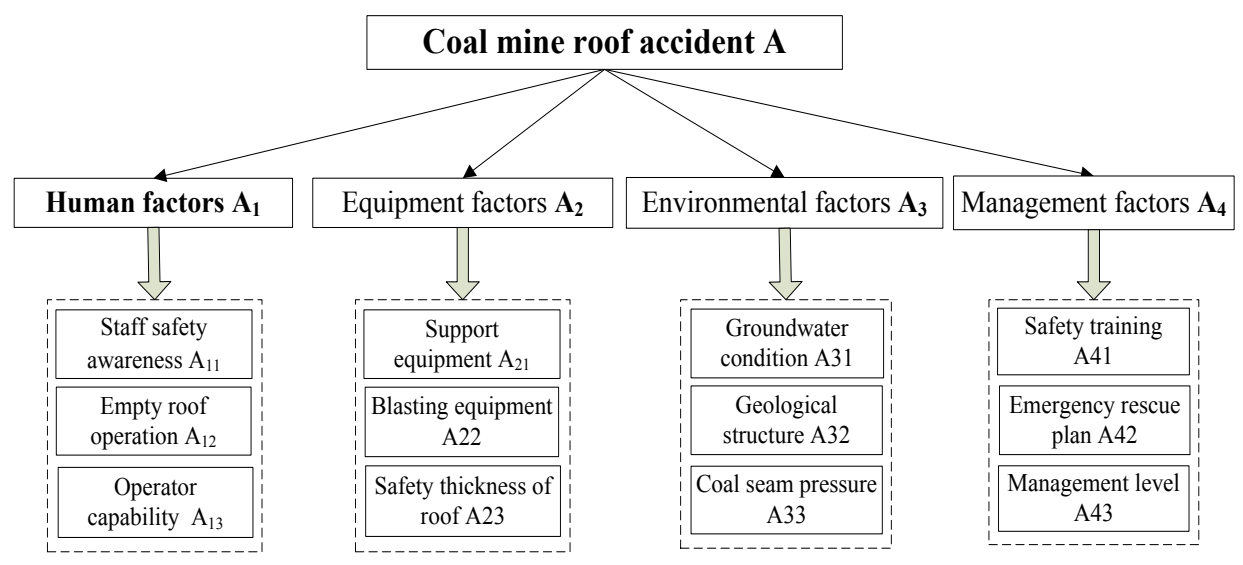

Figure 1 Risk assessment index system of coal mine roof accident

\section{Risk assessment model of coal mine roof accident}

\subsection{Risk assessment factor set and comment set of roof accident}

Grey fuzzy evaluation is a comprehensive evaluation method, which is based on fuzzy mathematics theory ${ }^{[16,17]}$. It can transform the qualitative evaluation of the problem into the quantitative evaluation, and can better solve the difficult to quantify safety evaluation problems. Its basic step is to use grey relation analysis ${ }^{[18-21]}$ to determine the weight coefficient ${ }^{[22-24]}$ of each influencing factor in the evaluation index system, use the expert scoring method to obtain the fuzzy evaluation matrix, calculate the correlation degree of the index, and finally carry on the fuzzy operation to get the fuzzy evaluation result. This method is simple in calculation, clear in result, and has high feasibility and credibility. The 
evaluation of coal mine roof accident is a qualitative and complex process. The method of grey fuzzy evaluation can simplify the complex problems, so the method of grey fuzzy combination is feasible.

In the grey fuzzy comprehensive evaluation of coal mine roof accidents, the first thing is to determine the factor set of the evaluation object. Suppose $A=\left\{A_{1}, A_{,}, \cdots A_{m}\right\}$, among $i=1,2, \cdots, m$, It represents the evaluation indicators in the evaluation process, that is, the influencing factors in the indicator system constructed above.

In addition, we need to determine the comment set of the evaluation object, suppose $V=\left\{v_{1}, v_{1}, \cdots v_{n}\right\}$, among $i=1,2, \cdots, n$, It indicates the evaluation results of this evaluation. Generally, the evaluation results are divided into five grades: very safe, relatively safe, generally safe, relatively dangerous and very dangerous. These five levels can form a comment set: $V=\left(V_{\mathrm{I}}, V_{\mathrm{II}}, V_{\mathrm{III}}, V_{\mathrm{IV}}, V_{\mathrm{V}}\right)$, The values are $10-8,8-6,6-4,4-2$ and 2-0 respectively. In the middle, they are recorded as $9,7,5,3$ and 1 , which can be expressed as $V=\left(\begin{array}{lllll}9 & 7 & 5 & 3 & 1\end{array}\right)^{T}$.

Then, the weight vector of each evaluation factor is determined. In this paper, the gray correlation analysis method is selected to evaluate the specific evaluation indexes of the coal mine.

First of all, in the evaluation index system, the first level is the factor set of basic index evaluation,It can be expressed as $A=\left\{A_{1}, A_{2}, A_{3}, A_{4}\right\}$. Then the second level is the factor index factor, which can be recorded as

$$
\begin{aligned}
& A_{1}=\left\{A_{11}, A_{12}, A_{13}\right\}, A_{2}=\left\{A_{21}, A_{22}, A_{23}\right\}, \\
& A_{3}=\left\{A_{31}, A_{32}, A_{33}\right\}, A_{4}=\left\{A_{41}, A_{42}, A_{43}\right\} .
\end{aligned}
$$

\subsection{Determination of index weight based on Grey Relation Analysis}

The grey correlation analysis method is used to calculate the correlation coefficient and correlation degree ${ }^{[25,26]}$ of the evaluation index, so as to obtain the weight coefficient and establish the weight matrix, as shown in Table 1 below. 
Table 1. Evaluate the weight of index system

\begin{tabular}{|c|c|c|c|c|c|}
\hline $\begin{array}{c}\text { Basic } \\
\text { indicators }\end{array}$ & $\begin{array}{c}\text { Basic } \\
\text { index } \\
\text { weight }\end{array}$ & Influence factors & $\begin{array}{c}\text { Correlatio } \\
\text { n degree }\end{array}$ & $\begin{array}{c}\text { Comprehens } \\
\text { ive weight }\end{array}$ & $\begin{array}{l}\text { Weight of } \\
\text { influencing } \\
\text { factors }\end{array}$ \\
\hline \multirow{3}{*}{$\begin{array}{l}\text { Human } \\
\text { factors }\end{array}$} & \multirow{3}{*}{0.2528} & Staff safety awareness & 0.7703 & 0.0826 & 0.3267 \\
\hline & & Empty roof operation & 0.8051 & 0.0863 & 0.3415 \\
\hline & & Operator capability & 0.7822 & 0.0839 & 0.3318 \\
\hline \multirow{3}{*}{$\begin{array}{c}\text { Equipment } \\
\text { factors }\end{array}$} & \multirow{3}{*}{0.2501} & Support equipment & 0.7761 & 0.0832 & 0.3327 \\
\hline & & Blasting equipment & 0.7740 & 0.0830 & 0.3318 \\
\hline & & Safety thickness of roof & 0.7825 & 0.0839 & 0.3355 \\
\hline \multirow{3}{*}{$\begin{array}{l}\text { Environme } \\
\text { ntal factors }\end{array}$} & \multirow{3}{*}{0.2517} & Groundwater situation & 0.8973 & 0.0962 & 0.3822 \\
\hline & & Geological structure & 0.7761 & 0.0832 & 0.3306 \\
\hline & & Coal seam pressure & 0.6745 & 0.0723 & 0.2873 \\
\hline \multirow{3}{*}{$\begin{array}{l}\text { Manageme } \\
\text { nt factors }\end{array}$} & \multirow{3}{*}{0.2454} & Safety training & 0.8401 & 0.0901 & 0.3671 \\
\hline & & Emergency rescue plan & 0.6782 & 0.0727 & 0.2963 \\
\hline & & Management level & 0.7703 & 0.0826 & 0.3366 \\
\hline
\end{tabular}

The weight matrix can be obtained from the above weight coefficient table:

$$
\begin{aligned}
& A_{1}=\left(\begin{array}{lll}
0.3267 & 0.3415 & 0.3318
\end{array}\right)^{T}, A_{2}=\left(\begin{array}{llll}
0.3327 & 0.3318 & 0.3355
\end{array}\right)^{T}, \\
& A_{1}=\left(\begin{array}{lll}
0.3267 & 0.3415 & 0.3318
\end{array}\right)^{T}, A_{4}=\left(\begin{array}{llll}
0.3671 & 0.2963 & 0.3366
\end{array}\right)^{T} .
\end{aligned}
$$

\section{Establishment of fuzzy comprehensive evaluation model}

\subsection{Expert scoring method to establish evaluation sample matrix}

Employ 10 experts, and calculate the membership matrix ${ }^{[27,28]}$ according to the risk evaluation matrix $\left(M_{i j}\right)_{k \times m}$ obtained by the experts scoring the above 12 evaluation indexes. 


$$
\left(M_{i j}\right)_{k \times m}=\left|\begin{array}{llllllllllll}
6 & 8 & 7 & 9 & 8 & 6 & 9 & 8 & 7 & 10 & 8 & 7 \\
9 & 7 & 9 & 9 & 8 & 7 & 5 & 7 & 6 & 8 & 7 & 6 \\
7 & 8 & 6 & 6 & 8 & 9 & 6 & 7 & 7 & 8 & 6 & 9 \\
5 & 8 & 5 & 8 & 8 & 7 & 9 & 6 & 6 & 8 & 9 & 7 \\
6 & 7 & 7 & 8 & 7 & 7 & 6 & 9 & 8 & 5 & 9 & 5 \\
6 & 6 & 9 & 7 & 8 & 7 & 8 & 8 & 5 & 7 & 9 & 8 \\
9 & 5 & 6 & 8 & 9 & 5 & 7 & 6 & 8 & 7 & 7 & 6 \\
8 & 7 & 7 & 8 & 6 & 8 & 9 & 7 & 7 & 6 & 8 & 5 \\
7 & 5 & 6 & 6 & 5 & 4 & 6 & 9 & 8 & 7 & 6 & 7 \\
6 & 8 & 9 & 7 & 8 & 6 & 7 & 7 & 9 & 6 & 8 & 8
\end{array}\right|
$$

\subsection{Fuzzy comprehensive evaluation}

\subsubsection{Single factor fuzzy evaluation}

First of all, the single factor in the evaluation index system is evaluated, and the relationship matrix between the evaluation sets of this factor set is obtained, that is, the single factor fuzzy evaluation. The membership matrix of the evaluation index is obtained by calculating the grey and white weight coefficients of the above-mentioned experts' scoring results.

The corresponding membership matrix of human factors $\mathrm{A}_{1}$ in the mine:

$$
S_{1}=\left[\begin{array}{lllll}
0.7229 & 0.2530 & 0.0241 & 0.0000 & 0.0000 \\
0.7595 & 0.1899 & 0.0506 & 0.0000 & 0.0000 \\
0.7500 & 0.2250 & 0.0250 & 0.0000 & 0.0000
\end{array}\right]
$$

The corresponding membership matrix of material factors $\mathrm{A}_{2}$ :

$$
S_{2}=\left[\begin{array}{lllll}
0.8696 & 0.1304 & 0.0000 & 0.0000 & 0.0000 \\
0.8451 & 0.1268 & 0.0282 & 0.0000 & 0.0000 \\
0.6853 & 0.2480 & 0.0699 & 0.0000 & 0.0000
\end{array}\right]
$$

The corresponding membership matrix of environmental factors $\mathrm{A}_{3}$ :

$$
S_{3}=\left[\begin{array}{lllll}
0.7643 & 0.2102 & 0.0255 & 0.0000 & 0.0000 \\
0.8333 & 0.1667 & 0.0000 & 0.0000 & 0.0000 \\
0.7792 & 0.1948 & 0.0260 & 0.0000 & 0.0000
\end{array}\right]
$$

The corresponding membership matrix of management factors $\mathrm{A}_{4}$ :

$$
S_{4}=\left[\begin{array}{lllll}
0.7792 & 0.1948 & 0.0260 & 0.0000 & 0.0000 \\
0.8696 & 0.1304 & 0.0000 & 0.0000 & 0.0000 \\
0.7186 & 0.2335 & 0.0479 & 0.0000 & 0.0000
\end{array}\right]
$$

According to the weight coefficient and membership matrix of the evaluation index calculated above, a single factor fuzzy comprehensive evaluation is made.

The single factor fuzzy comprehensive evaluation of the risk level evaluation of human factors $\mathrm{A}_{1}$ in the mine is as follows: 


$$
\begin{aligned}
& B_{1}=A_{1} S_{1}=\left(\begin{array}{lll}
0.3267 & 0.3415 & 0.3318
\end{array}\right)\left[\begin{array}{lllll}
0.7229 & 0.2530 & 0.0241 & 0.0000 & 0.0000 \\
0.7595 & 0.1899 & 0.0506 & 0.0000 & 0.0000 \\
0.7500 & 0.2250 & 0.0250 & 0.0000 & 0.0000
\end{array}\right] \\
& =\left(\begin{array}{lllll}
0.7444 & 0.2222 & 0.0334 & 0.0000 & 0.0000
\end{array}\right)
\end{aligned}
$$

The single factor fuzzy comprehensive evaluation of risk level evaluation of material factors $\mathrm{A}_{2}$ is as follows:

$$
\begin{aligned}
& B_{2}=A_{2} S_{2}=\left(\begin{array}{lll}
0.3327 & 0.3318 & 0.3355
\end{array}\right)\left[\begin{array}{llllll}
0.8696 & 0.1304 & 0.0000 & 0.0000 & 0.0000 \\
0.8451 & 0.1268 & 0.0282 & 0.0000 & 0.0000 \\
0.6853 & 0.2448 & 0.0699 & 0.0000 & 0.0000
\end{array}\right] \\
& =\left(\begin{array}{lllll}
0.7996 & 0.1676 & 0.0328 & 0.0000 & 0.0000
\end{array}\right)
\end{aligned}
$$

The single factor fuzzy comprehensive evaluation of risk level evaluation of environmental factors $\mathrm{A}_{3}$ is as follows:

$$
\begin{aligned}
& B_{3}=A_{3} S_{3}=\left(\begin{array}{lll}
0.3822 & 0.3306 & 0.2873
\end{array}\right)\left[\begin{array}{llllll}
0.7643 & 0.2102 & 0.0255 & 0.0000 & 0.0000 \\
0.8333 & 0.1667 & 0.0000 & 0.0000 & 0.0000 \\
0.7792 & 0.1948 & 0.0260 & 0.0000 & 0.0000
\end{array}\right] \\
& =\left(\begin{array}{lllll}
0.7915 & 0.1914 & 0.0172 & 0.0000 & 0.0000
\end{array}\right)
\end{aligned}
$$

The single factor fuzzy comprehensive evaluation of risk level evaluation of management factors $\mathrm{A}_{4}$ is as follows:

$$
\begin{aligned}
& B_{4}=A_{4} S_{4}=\left(\begin{array}{lll}
0.3671 & 0.2963 & 0.3366
\end{array}\right)\left[\begin{array}{llllll}
0.7792 & 0.1948 & 0.0260 & 0.0000 & 0.0000 \\
0.8696 & 0.1304 & 0.0000 & 0.0000 & 0.0000 \\
0.7186 & 0.2335 & 0.0479 & 0.0000 & 0.0000
\end{array}\right] \\
& =\left(\begin{array}{lllll}
0.7813 & 0.1873 & 0.0254 & 0.0000 & 0.0000
\end{array}\right)
\end{aligned}
$$

From the above single factor evaluation, the following evaluation matrix can be obtained:

$$
S=\left(\begin{array}{l}
B_{1} \\
B_{2} \\
B_{3} \\
B_{4}
\end{array}\right)=\left(\begin{array}{lll}
A_{1} & \cdot & S_{1} \\
A_{2} & \cdot & S_{2} \\
A_{3} & \cdot & S_{3} \\
A_{4} & \cdot & S_{4}
\end{array}\right)=\left[\begin{array}{lllll}
0.7444 & 0.2222 & 0.0334 & 0.0000 & 0.0000 \\
0.7996 & 0.1676 & 0.0328 & 0.0000 & 0.0000 \\
0.7915 & 0.1914 & 0.0172 & 0.0000 & 0.0000 \\
0.7813 & 0.1873 & 0.0254 & 0.0000 & 0.0000
\end{array}\right]
$$

\subsubsection{Two level fuzzy comprehensive evaluation}

The six basic indicators in the indicator system are regarded as comprehensive factors, and the risk objective a is evaluated by two-level fuzzy comprehensive evaluation. The results are as follows:

$$
\begin{aligned}
& B=A S=\left(\begin{array}{llll}
0.2528 & 0.2501 & 0.2517 & 0.2454
\end{array}\right)\left[\begin{array}{llllll}
0.7444 & 0.2222 & 0.0334 & 0.0000 & 0.0000 \\
0.7996 & 0.1676 & 0.0328 & 0.0000 & 0.0000 \\
0.7915 & 0.1914 & 0.0172 & 0.0000 & 0.0000 \\
0.7813 & 0.1873 & 0.0254 & 0.0000 & 0.0000
\end{array}\right] \\
& =\left(\begin{array}{lllll}
0.7791 & 0.1922 & 0.0271 & 0.0000 & 0.0000
\end{array}\right)
\end{aligned}
$$

Then the evaluation result is:

$$
Z=B V^{T}=\left(\begin{array}{llllll}
0.7791 & 0.1922 & 0.0271 & 0.0000 & 0.0000
\end{array}\right)\left(\begin{array}{lllll}
9 & 7 & 5 & 3 & 1
\end{array}\right)^{T}=8.4928
$$


The comprehensive evaluation results show that the safety level of the coal mine is very safe.

\section{Countermeasures for risk control of coal mine roof accidents}

The grey fuzzy comprehensive evaluation results show that the mine is in a very safe level, but from the grey correlation analysis of the evaluation indexes, it can be seen that there are still some single factors with relatively low evaluation grades. Therefore, based on the above evaluation results and the expert scores of single indexes, the following measures are proposed for the risk control of roof accidents in the mine:

(1)Through safety awareness education, improve the awareness of prevention of the importance of roof accidents, put an end to unnecessary unsafe behaviors; at the same time, improve safety skills training, improve the ability of underground operators to discover roof accidents in time and self rescue skills. In the production and construction, we should strictly abide by the rules. The safety awareness and quality of employees are the most important aspects to avoid the mine roof accidents and other accidents. If we can timely train and strengthen the safety management, the accidents caused by the mistakes of employees will be greatly reduced.

(2)Regularly overhaul and maintain relevant support equipment, find out problems in time to avoid safety accidents, be alert to the real-time monitoring of the roof, improve the preparation work before driving, standardize and reasonably design the support, and replace the unqualified equipment in time.

(3)Perfect safety management system is the legal requirement of enterprise production. This paper discusses the roof, and considers the measures that enterprises can take according to the possible accidents. Establish and improve the effective management mechanism, strengthen the training and education of the relevant staff, formulate the relevant management regulations, improve the responsibility system, establish the relevant responsibility system from the four aspects of human, material, environment and management, improve the safety awareness of the staff and ensure the prevention and emergency measures of coal mine roof accidents.

\section{Conclusion}

In this paper, the risk assessment of coal mine roof accidents is carried out, and the main conclusions are as follows:

(1) Based on the theory of safety management, paper identifies the risk of accounting agency accidents from four aspects: human factors, equipment factors, environmental factors and management factors, and establishes a risk evaluation index system. The scope of index identification is wide and the content of evaluation is comprehensive.

(2) Based on the establishment of risk index system, the weight of this evaluation index set is determined by the method of grey correlation analysis, and the fuzzy comprehensive evaluation model of mine roof accident is obtained by the method of fuzzy comprehensive evaluation. The comprehensive correlation degree of the index to mine roof accident is calculated by the combination of the two methods.

(3)According to the correlation degree of four kinds of hazard sources to accidents, the hazard sources that should be considered first in accident prevention and control can be determined, so that targeted measures can be taken. Through the empirical study on the risk assessment of the mine roof accident, it is concluded that the safety level of the mine is very safe. This assessment provides a theoretical guidance for the risk assessment of the mine roof accident. 


\section{References}

1. H. Liu, Z.H. Zeng, Inner Mongolia coal economy-2019, 06, 92 (2019)

2. H.S.B Duzgun, H.H. Einstein, Safety Science, 42:1, 23 (2004)

3. S. K. Palei, S. K. Das, International Journal of Coal Geology, 75:4, 241 (2008)

4. J. Maiti, V. Vivek Khanzode, Safety Science, 47:8, 1068 (2009)

5. S. Mahdevari, K. Shahriar, A. Esfahanipour, Science of The Total Environment, 488:489, 85 (2014)

6. S Behraftar, S. M. F. Hossaini, E. Bakhtavar, Journal of the Geological Society of India, 90:2, 196 (2017)

7. P. Avinash, R. Murthy, V.Mallika Sita, P.Amar, A. Kumar, Current Science, 114:10, 2167 (2018)

8. T. W. Zhang, X. M. Wu, Coal technology, 30:07, 74 (2011)

9. W.B. Jiang, F. Qu, L. Zhang, 2012 International symposium on safety science and technology, 45, 83 (2012)

10. W. C. Wang, Z. Q. Yang, Inner Mongolia coal economy, 09, 27 (2016)

11. J. L. Xie, J. L Xu, W. B. Zhu, Arabian Journal of Geosciences, 9:8 (2016)

12. Y. B Guan, X. H Wang, S.W. Guo, World Journal of Engineering, 14:2, 121 (2017)

13. X. Zhang, P. Gong, K. Wang, J. Li, Y. Jiang, Rock Mechanics and Rock Engineering, 52:8, 2775 (2019)

14. D. Xu, Energy and energy saving, 2019:12, 124 (2019)

15. L. X. Guo, X. J. Li, Z. Liu, Coal engineering, 52:03, 172 (2020)

16. X. Y. Guo, Sichuan Architecture, 39:04, 117 (2019)

17. X. Y. Ji, H. L.Wang, X. L., Xu, F. Hu, J. T. Liang, Science Technology and Engineering, 19:20, 49 (2019)

18. S. Wang, J. Zhang, Study Journal of Coal Science and Engineering (China), 14:1, 81 (2008)

19. B. Li, Y. H. Bi, X. W. Liu, Engineering Blasting, 24:04, 86 (2018)

20. M. Qiu, L. Shi, C. Teng, Y. Zhou, Mine Water and the Environment, 36:1, 39-50(2016)

21. X. Qu, M. Qiu, J. Liu, Z. Niu, X. Wu, Arabian Journal of Geosciences, 12:18, ( 2019)

22. X. X. Li, K. S. Wang, L. W Liu, Procedia engineering, 26 (2011)

23. W. K. Luo, S. L Shi, Y. Lu, S. H Zou, Z. A Chen, L.L. Chen, Journal of Geoscience and Environment Protection, 1, 154 (2016)

24. X. Gao, K. L Ma, H. Wang, Q. Gao, L .J. Lei, T. Wang, Scientific Reports, 9:1 ( 2019)

25. M. J. Fabiańska, S. R. Ćmiel, M. Misz-Kennan, International Journal of Coal Geology, 107, 96 (2016)

26. A. D. Kamble, V. K. Saxena, P. D. Chavan, B. D. Singh, V. A. Mendhe, Journal of the Energy Institute, 92:4, 982 (2019)

27. S. Shi, B. Jiang, X. Meng, International Journal of Mining Science and Technology. 28:6, 991 (2018)

28. X. Liang, W. Liang, L. Zhang, X. Guo, Journal of Cleaner Production, 227, 218 (2019) 